\title{
ORIGINAL
}

\section{The value of Neutrophil gelatinase-associated lipocalin and Neutrophil/Lymphocyte Ratio in the diagnosis of preeclampsia and its severity}

\author{
Eham Amer Ali', Ban Hadi Hameed², and Alea Farhan Salman ${ }^{3}$ \\ ${ }^{1}$ Ass. Prof. Department of Chemistry and Biochemistry, College of Medicine/Mustansiriyah University, Baghdad, Iraq, ${ }^{2}$ Ass. Prof. Department \\ of Gynaecology And Obstetrics, Mustansiriyah university \College of medicine, Baghdad, Iraq, ${ }^{3}$ Lecturer Alea Farhan Salman, The National \\ Centre of Haematology, Mustansiriyah University, Baghdad, Iraq
}

\begin{abstract}
Many hypotheses underlie the pathogenesis of preeclampsia. This study aims to evaluate Neutrophil gelatinase-associated lipocalin (a marker of immune hypothesis) and Neutrophil/Lymphocyte ratio (a marker of inflammation) in the diagnosis of preeclampsia and its severity and to determine the correlation between them. Study design : This randomized case-control study involved 132 pregnant women; 88 were diagnosed with PE (divided into non-severe and severe groups), and 44 healthy pregnant women as a control group. Results : The mean serum level of NGL was significantly higher in PE $(535.37 \pm 158.61 \mathrm{ng} / \mathrm{ml}$ for severe PE, $522.5 \pm 106.3 \mathrm{ng} / \mathrm{ml}$ for non-severe PE, and $161.96 \pm 17.48 \mathrm{ng} / \mathrm{ml}$ for the control group). The ROC Curve NGL criteria of more than $204.4 \mathrm{ng} / \mathrm{ml}$ showed $100 \%$ sensitivity and specificity in both severe and non-severe cases versus control. The N/L ratio showed a significant difference (5.81 \pm 5.24 for severe $\mathrm{PE}, 4.1 \pm 3.41$ for non-severe $\mathrm{PE}$, and $3.89 \pm 1.79$ for the control group), but the ROC curve criterion was not significant. Both showed a non-significant positive correlation. Conclusion : NGL is an excellent diagnostic factor, whereas N/L might have lower diagnostic performance compared with NGL. Both are related independently to the pathophysiology of PE. J. Med. Invest. $68: 321-325$, August, 2021
\end{abstract}

Keywords : Neutrophil gelatinase-associated lipocalin, Preeclampsia, Neutrophil/lymphocyte ratio

\section{INTRODUCTION}

Preeclampsia $(\mathrm{PE})$ is a common significant health issue affecting pregnant women for which the placenta has been accused as the cause of its systemic effects on the mother and fetus (1). After twenty weeks of gestation, it is characterized by new-onset hypertension and an increased level of protein secretion in urine. It is one of the major causes for restricted fetal growth, multi-organ maternal affection, and even mortality of both the mother and the fetus in severe cases (2). Approximately five to ten percent of pregnancies worldwide are affected by preeclampsia (3). The exact pathogenesis remains controversial; however, the impaired coagulation-fibrinolysis systems, abnormal immune responses, and inflammation are often mentioned in addition to the abnormal gestational trophoblast cell invasion and endothelial cell injuries, which are also widely studied $(4,5)$.

In general, possible mechanisms presented to elucidate the pathophysiology behind preeclampsia included : abnormal remodeling of the spiral arteries, abnormal trophoblast differentiation, and abnormal placentation with the resulting hypoxia, placental hypoperfusion, and ischemia (6). Some factors have key roles in the pathogenesis of $\mathrm{PE}$, for example, genetic factors, immunological factors, inflammation, and systemic endothelial damage (7).

The wide diversity of mechanisms that underlie the pathophysiology of $\mathrm{PE}$ directed the researchers to investigate the usefulness of combined biomarkers analysis in the enhancement

Received for publication May 12, 2021 ; accepted July 1, 2021.

Address correspondence and reprint requests to Dr. Ban Hadi Hameed, Mustansiriyah university, P O Box : 14022. of their diagnostic performance (8). Neutrophil gelatinase-associated lipocalin (NGL) is a $25-\mathrm{KDa}$ protein of the lipocalin family and is considered a biomarker for ischemic injury. It was used as a biomarker for diagnosing acute kidney injury and was linked to the immune pathway of PE $(8,9)$. Very few studies have been conducted on serum NGL in human pregnancy. However, the characteristics of this molecule, which increases in hypertensive pregnant women and correlates with angiogenic factors, imply that NGL might be related to the pathogenesis of preeclampsia and eclampsia. The increase in NGL level in blood during the second trimester of pregnancy is a sensitive indicator for the occurrence of preeclampsia $(10,11)$. The kidney injury, proteinuria, and endothelial inflammatory reactions in preeclampsia represent the possible role of NGL in PE pathogenesis.

This study evaluated the Neutrophil/lymphocyte ratio (N/L), one of the markers of systemic inflammation and a hot research point in recent years, as it is involved in developing various diseases related to the prognosis of neoplasms (12). The complete blood count (CBC) parameter of inflammation and/or ischemia is the ratio of absolute neutrophils count to the absolute count of lymphocytes. It is a sign of the body's immune response to offending factors. It is also a quick, cost-effective, and straightforward parameter that indicates systemic inflammation and stress (13). The relation of this ratio with $\mathrm{PE}$ was evaluated in many studies with contradicting results due to the study's different design and sampling (14). The combination of two important mechanisms in the pathogenesis of $\mathrm{PE}$ that are abnormal immune response and inflammation is the cornerstone behind evaluating these two variables in the current study which aims to assess the diagnostic performance of NGL and N/L in PE and to investigate their prognostic utility to determine disease severity on the same sample of pregnant women and to determine the correlation of these two variables in the pathophysiology of PE. 


\section{PATIENTS AND METHOD}

A case-control study had been conducted at Al Yarmouk teaching hospital/Baghdad \Iraq, for six months from August 2020 till February 2021. The study enrolled 132 women who were allocated into three groups : 44 cases with severe PE, 44 cases with non-severe $\mathrm{PE}$, and 44 pregnant normotensive women as a control group, the maternal age and gestational age were matched to minimize the effect of these variables on the study.

The patients were newly diagnosed cases selected from the Obstetric ward and outpatient clinic who fill the diagnostic criteria of PE : blood pressure (BP) equal or more than 140/90 $\mathrm{mmHg}$ after 20 weeks in previously normotensive women with proteinuria of $300 \mathrm{mg} / 24 \mathrm{~h}$ or more. The following features specify the patients in the severe PE group : systolic BP equal or more than $160 \mathrm{mmHg}$, diastolic $\mathrm{BP}$ equal or more than $110 \mathrm{mmHg}$, headache, visual disturbances, upper abdominal pain, oliguria, convulsion, elevated serum creatinine, thrombocytopenia < $100,000 / \mu \mathrm{L}$, elevated serum transaminase, fetal-growth restriction, and pulmonary edema. Whereas the absence of severe features categorizes the patients for non-severe PE (15).

The study's protocol was approved by the medical of Mustansiriyah University (MOG 112 on 22 July 2020). Informed consent had been obtained from all participants before enrolment in the study.

Thorough Obstetric history and complete physical examination had been performed to document the demographic and clinical criteria. Body mass index (BMI) was calculated as follows : Weight $(\mathrm{kg}) /$ Height $\left(\mathrm{m}^{2}\right)$, blood pressure $(\mathrm{BP})$ record in sitting or semi-sitting position using a mercurial sphygmomanometer to document both systolic BP (SBP) and diastolic BP (DBP). A blood sample was taken by venepuncture, centrifuged, and kept in the freezer till analysis for all participants. Complete blood count, renal function, liver function, and urine analysis were performed, and NGL assay by ELISA.

\section{Statistical Analysis}

The data were analyzed using a statistical package for social science (SPSS 24). Parametric data were analyzed using One-Way ANOVA and posthoc Scheffe tests whereas the non-parametric data were analyzed using the Kruskal-Wallis test. The inter-assay coefficient of variability for NGL was $10.7 \%$ whereas the intra-assay coefficient of variability was $8.5 \%$ with a sensitivity of $92 \%$. Spearman's correlation was used to determine the correlation coefficient between NGL and N/L ratio. A P-value less than 0.05 was considered significant.

\section{RESULTS}

The study groups' demographic, clinical, and biochemical variables are clarified in table 1, showing a significantly higher BMI, SBP, DBP, liver enzymes, and renal function parameters in PE groups compared to the control group as $\mathrm{p}$ values were less than 0.05 .

Regarding NGL, the study showed a highly significant rise in this biomarker in PE cases when compared with the control group $(535.37 \pm 158.61) \mathrm{ng} / \mathrm{ml}$ for severe PE, $(522.5 \pm 106.3)$ $\mathrm{ng} / \mathrm{ml}$ for non-severe PE, and $(161.96 \pm 17.48) \mathrm{ng} / \mathrm{ml}$ for the control group) as the p-value was less than 0.001 . The neutrophil/lymphocyte ratio showed a significant difference among the study groups $(5.81 \pm 5.24)$ for severe PE, $(4.1 \pm 3.41)$ for non-severe $\mathrm{PE}$, and $(3.89 \pm 1.79)$ for the control group, and the $\mathrm{p}$-value was 0.027 as shown in table 2 .

The ROC curve calculated the NGL criterion value for diagnosing $\mathrm{PE}$ for severe and non-severe cases versus control, clarified in figures 1 and 2. For both severe and non-severe PE cases at a more than $204.4 \mathrm{ng} / \mathrm{ml}$ criterion, the sensitivity and specificity were $100 \%$, suggesting an excellent diagnostic marker as the area under the curve (AUC) was $1.00,95 \%$ confidence interval (0.92-1.00), P-value $<0.001$.

Despite the significant difference in N/L ratio among the study groups, the ROC curve showed a non-significant criterion for severe and non-severe cases as $\mathrm{P}$-values were more than 0.05 , AUC 0.56, and 95\% confidence interval (0.4-0.7), P-value 0.46 as shown in figures 3 and 4 .

Spearman's correlation revealed a weak positive non-significant correlation between NGL and N/L ratio with a correlation coefficient of 0.107 and P-value 0.39 as shown in table 3.

Table 1. The demographic, clinical, and biochemical variables of the study groups

\begin{tabular}{|l|c|c|c|c|}
\hline \multicolumn{1}{|c|}{$\begin{array}{c}\text { Variable } \\
\text { (Mean } \pm \text { SD) }\end{array}$} & $\begin{array}{c}\text { Severe PE } \\
\text { Number 44 }\end{array}$ & $\begin{array}{c}\text { Non-severe } \\
\text { PE Number } \\
\mathbf{4 4}\end{array}$ & $\begin{array}{c}\text { Control } \\
\text { Number 44 }\end{array}$ & $\begin{array}{c}\text { P-Values } \\
\text { ANOVA }\end{array}$ \\
\hline Age (years) & $28.59 \pm 7.84$ & $26.63 \pm 6.85$ & $27.36 \pm 5.4$ & 0.096 \\
\hline Gestational age (weeks) & $35.81 \pm 1.78$ & $36.31 \pm 1.93$ & $35.13 \pm 2.56$ & 0.644 \\
\hline Parity & $1.59 \pm 2.06$ & $1.6 \pm 1.86$ & $1.5 \pm 1.18$ & 0.084 \\
\hline Pre-pregnancy BMI $\left(\mathrm{Kg} / \mathrm{m}^{2}\right)$ & $24.56 \pm 1.67$ & $25.75 \pm 2.43$ & $28.54 \pm 2.54$ & 0.72 \\
\hline Weight in pregnancy $(\mathrm{Kg})$ & $92.43 \pm 7.62$ & $85.95 \pm 12.05$ & $87.58 \pm 9.23$ & 0.307 \\
\hline Weight gain during pregnancy $(\mathrm{Kg})$ & $12.34 \pm 4.24$ & $11.87 \pm 4.65$ & $9.54 \pm 5.46$ & 0.14 \\
\hline SBP $(\mathrm{mmHg})$ & $163 \pm 7.85$ & $144 \pm 5.09$ & $115 \pm 5.9$ & $<0.001$ \\
\hline DBP $(\mathrm{mmHg})$ & $105 \pm 9.59$ & $96.36 \pm 7.26$ & $80 \pm 6.17$ & 0.005 \\
\hline SGOT $(\mathrm{IU} / \mathrm{L})$ & $35.75 \pm 38.22$ & $20.53 \pm 7.78$ & $19.02 \pm 5.9$ & 0.032 \\
\hline SGPT $(\mathrm{IU} / \mathrm{L})$ & $25.89 \pm 18.6$ & $17.87 \pm 8.6$ & $18.51 \pm 5.6$ & 0.03 \\
\hline B. urea $(\mathrm{mg} / \mathrm{dl})$ & $24.38 \pm 8.46$ & $19.39 \pm 7.44$ & $19.32 \pm 6.76$ & 0.047 \\
\hline S. creatinine $(\mathrm{mg} / \mathrm{dl})$ & $0.78 \pm 0.13$ & $0.65 \pm 0.12$ & $0.69 \pm 0.1$ & 0.003 \\
\hline
\end{tabular}

Abbreviations : BMI : Body mass index, SBP : Systolic blood pressure, DBP : Diastolic blood pressure, SGOT : Serum glutamic-oxaloacetic transaminase, SGPT : Serum glutamic-pyruvic transaminase, B. urea : Blood urea, S. creatinine : Serum creatinine. 
Table 2. Comparison of NGL and N/L ratio among the study groups

\begin{tabular}{|c|c|c|c|c|c|c|}
\hline & \multicolumn{5}{|c|}{ Statistic } & \multirow{2}{*}{$\begin{array}{c}P \text {-Values } \\
\text { ANOVA }\end{array}$} \\
\hline & Groups & Number & Range & Mean & $S D$ & \\
\hline \multirow{3}{*}{$\begin{array}{l}\text { NGL } \\
(\mathrm{ng} / \mathrm{ml})\end{array}$} & controls & 44 & $142.13-180.54$ & 161.97 & 17.49 & \multirow{3}{*}{$<.001$} \\
\hline & $\begin{array}{c}\text { non-severe } \\
\text { PE }\end{array}$ & 44 & $410.5-633.23$ & 522.5 & 106.3 & \\
\hline & severe $\mathrm{PE}$ & 44 & $383.18-693.3$ & 535.37 & 158.62 & \\
\hline \multirow{3}{*}{$\begin{array}{l}\mathrm{N} / \mathrm{L} \\
\text { ratio }\end{array}$} & controls & 44 & $2.09-5.87$ & 3.90 & 1.80 & \multirow{3}{*}{0.027} \\
\hline & $\begin{array}{c}\text { non-severe } \\
\text { PE }\end{array}$ & 44 & $0.89-7.6$ & 4.10 & 3.41 & \\
\hline & severe PE & 44 & $0.68-11.04$ & 5.81 & 5.25 & \\
\hline
\end{tabular}

Abbreviations : SD : Standard deviation.

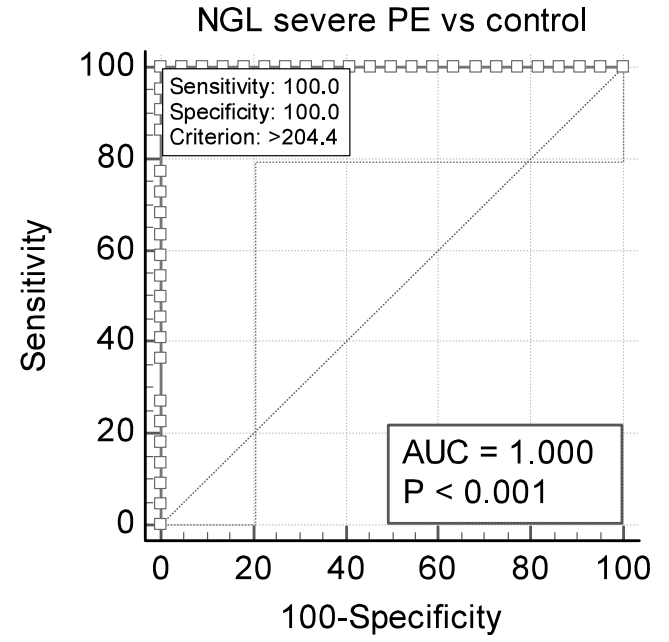

Figure 1. ROC Curve of NGL in severe PE cases versus control

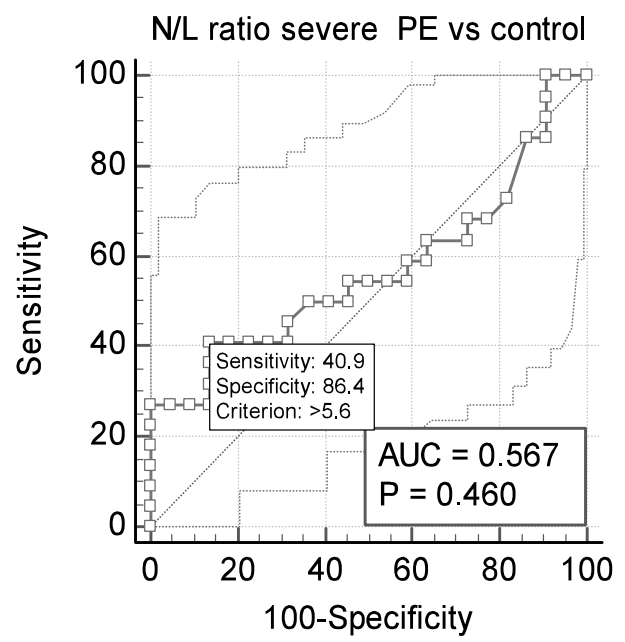

Figure 3. ROC Curve for $\mathrm{N} / \mathrm{L}$ ratio in severe $\mathrm{PE}$ versus control

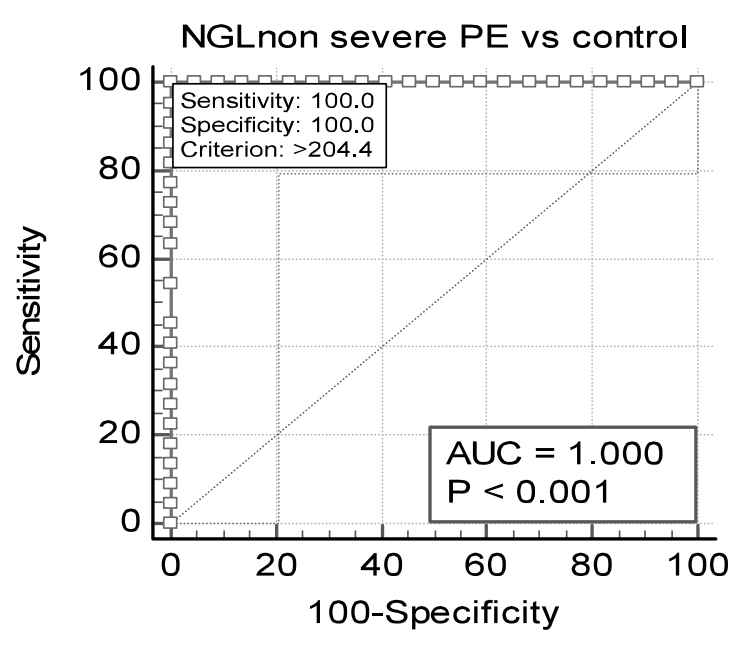

Figure 2. ROC Curve for NGL in non-severe PE versus control

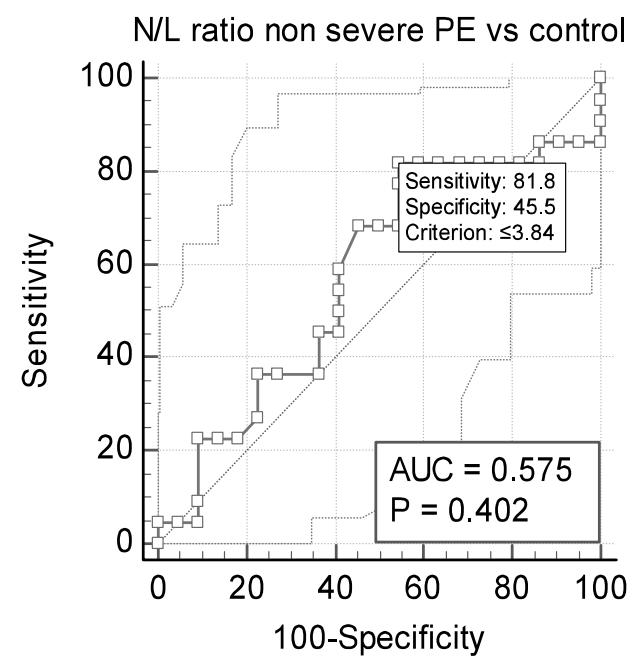

Figure 4. ROC curve for $\mathrm{N} / \mathrm{L}$ ratio in non-severe $\mathrm{PE}$ versus control 
Table 3. Spearman's Correlation between NGL and N/L ratio.

\begin{tabular}{|l|c|c|}
\hline Spearman's correlation & \multicolumn{2}{|c|}{ NGL } \\
\hline \multirow{2}{*}{ N/L } & Correlation Coefficient & 0.107 \\
\cline { 2 - 3 } & Sig. (2-tailed) & 0.390 \\
\hline
\end{tabular}

\section{DISCUSSION}

The estimation of Neutrophil gelatinase-associated lipocalin has been investigated by many researchers, as it is closely related to acute inflammatory conditions. The role of inflammation in the pathogenesis of $\mathrm{PE}$ is well established so that researchers had estimated NGL levels in PE (16).

Our study showed significantly higher serum NGL concentrations in preeclampsia cases as compared to normotensive pregnant women. These findings are consistent with Yalman et al. and Yolli et al., $(17,18)$. Karmapas et al. reported that NGL levels showed higher levels in pregnant women. However, in concordance with the results of our study, the increase in NGL in cases with PE was significantly higher than in normotensive pregnant women. Moreover, serum NGL levels were also raised in the first and second trimesters of pregnant women who later developed PE (19).

Interpretation of those findings in preeclampsia is that; vascular endothelial dysfunction leads to oxidative stress, ischemic placenta, systemic inflammation during pregnancy, and renal dysfunction. It is observed that NGL production occurs at the maternal-fetal interface (20). Consequently, serum NGL levels may increase in preeclampsia cases and can be utilized to assess PE progression and assess kidney functions. In contrast, Ahmad et al. (21) found a non-significant difference between the PE and control groups, but the sample size in this study was small. The same results were shown by Dhivya (22) study where nothing was mentioned about the severity of the disease.

Many studies linked the severity of inflammatory response in $\mathrm{PE}$ to the development of clinical symptoms. For example, activation of inflammatory cells and immune responses releases reactive oxygen species (ROS), inflammatory cytokines by the neutrophils, and lymphocytes, leading to endothelial dysfunction. Many papers addressed the association of N/L with pregnancy complications such as preeclampsia (23). Recently, neutrophil extracellular traps (NETs), sent out by neutrophils, was suggested to affect the development of the fetus in humans. NETs could take the space inside trophoblast villi causing fetal hypoxia by reducing blood flow. Another mechanism that includes the facilitation of NETs production is by activating endothelial cells, which damages the endothelium and may cause preeclampsia (24). The morbidity associated with severe disease necessitates predictive markers for preeclampsia severity, sill little of them proved significant.

In the present study, we aimed to assess the relation of N/L with the severity of preeclampsia. The N/L showed a highly significant rise in $\mathrm{PE}$ cases than the control group, in line with earlier studies $(25,26)$. Our findings support that N/L may serve as a promising diagnostic tool due to its significant elevation in $\mathrm{PE}$, especially in severe cases but the ROC curve criterion was not significant. At the same time, another study, in contrast to our study, showed a non-significant difference and ROC curve criterion between PE and control groups (14).

The value of $\mathrm{N} / \mathrm{L}$ in pregnancy was discussed in terms of predicting pregnancy outcomes in the first trimester. A study by Biyik I et al. showed a higher ratio in cases with missed miscarriage comparing to normal pregnancy (27). High ratio suggested an imbalance in the inflammatory reaction and it is assigned as a marker of severity in sepsis and inflammatory diseases (28).

As the severity of PE is the most important determinate of complications occurrence and in clinical work the discrimination of severe from non-severe cases is crucial, the present study summarizes the relationship between non-severe and severe cases of preeclampsia with the normotensive group by using the ROC curve to calculate the cut off value associated with the highest sensitivity and specificity for NGL and N/L ratio. The NGL was proved to be an excellent diagnostic biomarker with a $100 \%$ sensitivity and specificity in both severe and non-severe cases with no discrimination regarding the severity of the disease. The N/L showed a better performance for non-severe PE cases than severe PE cases as higher sensitivity was detected in non-severe cases. Whereas the results suggested that N/L might be a useful laboratory tool for clinical evaluation of disease severity due to high specificity $86.4 \%$ in severe cases. There was a weak positive non-significant correlation between the studied two parameters suggesting that they are related independently in the pathophysiology of $\mathrm{PE}$ contradicting another study that showed a significant correlation between them in cases with renal failure and heart disease (29).

\section{CONCLUSION}

NGL is an excellent diagnostic factor, whereas N/L might have lower diagnostic performance compared with NGL. The two variables are related independently in the pathophysiology of PE.

\section{ACKNOWLEDGMENT}

Our great appreciation for the valuable support of medical staff members at $\mathrm{Al}$ Mustansiriyah University and $\mathrm{Al}$ Yarmouk hospital.

\section{REFERENCES}

1. Tayyar AT, Karakus R, Eraslan Sahin M, Topbas NF, Sahin E, Karakus S, Yalcın ET, Tayyar A : Wnt signaling pathway in early- and late-onset preeclampsia : evaluation with Dickkopf-1 and R-Spondin-3 glycoproteins. Arch Gynecol Obstet 299(6) : 1551-1556, 2019

2. Nori W, Roomi AB, Akram W : Platelet indices as predictors of fetal growth restriction in Pre-eclamptic Women . Revista Latinoamericana de Hipertensión 15(4) : 280-285, 2020

3. Ahsan T, Banu S, Nahar Q, Ahsan M, Khan M, Islam S : Serum trace elements levels in preeclampsia and eclampsia : correlation with the pregnancy disorder. Biological Trace Element Research 152(3) : 327-332, 2013

4. Haire G, Egan K, Parmar K, McKinnon T, Monteith C, O'Connor H, Kevane B, Maguire P, Szklanna PB, Galligan M, Donnelly JC, Allen S, McCallion N, Hunt B, Áinle $\mathrm{FN}$ : Alterations in fibrin formation and fibrinolysis in early onset-preeclampsia : Association with disease severity. Eur J Obstet Gynecol Reprod Biol 241 : 19-23, 2019

5. Staff A, Johnsen G, Dechend R, Redman C : Preeclampsia and uteroplacental acute atherosis : immune and inflammatory factors. J Reprod Immunol 101-102 : 120-126, 2014

6. Fisher $\mathrm{S}$ : Why is placentation abnormal in preeclampsia. Am J Gynecol 213(4) : 115-122, 2015

7. Parry S, Mc Elrath T, Pucci D : "Clinical risk factors for preeclampsia in the 21st century”. Obstet Gynecol 124(4) : 763770,2014 
8. Liu N, Guo Y, Gong L, Wang B : Advances in biomarker development and potential application for preeclampsia based on pathogenesis. European Journal of Obstetrics \& Gynecology and Reproductive Biology $9: 3,2021$

9. Zhang J, Han J, Liu J, Liang B, Wang X, Wang C : Clinical significance of novel biomarker NGAL in early diagnosis of acute renal injury. Exp Ther Med 14 : 5017-5021, 2017

10. D'Anna R, Baviera G, Giordano D, Todarello G, Russo S, Recupero S, Bolignano D, Corrado F : Neutrophil gelatinase-associated lipocalin serum evaluation through normal pregnancy and in pregnancies complicated by preeclampsia. Acta Obstet Gynecol Scand 89(2) : 275-278, 2010

11. Yan J, Zeng X, Liu Q : Expression and significance of MMP-9 and NGAL in maternal serum and placental tissue in preeclampsia. J Pract Obstet Gynaecol 06 : 244, 2011

12. Thio QCBS, Goudriaan WA, Janssen SJ, Paulino Pereira NR, Sciubba DM, Rosovksy RP, Schwab JH : Prognostic role of neutrophil-to-lymphocyte ratio and platelet-to-lymphocyte ratio in patients with bone metastases. $\mathrm{Br} \mathrm{J}$ Cancer 119(6) : 737-743, 2018

13. Biyik I, Albayrak M, Keskin F : Platelet to Lymphocyte Ratio and Neutrophil to Lymphocyte Ratio in Missed Abortion. Rev Bras Ginecol Obstet 42(5) : 235-239, 2020

14. Yücel B, Ustun B: Neutrophil to lymphocyte ratio, platelet to lymphocyte ratio, mean platelet volume, red cell distribution width and plateletcrit in preeclampsia. Pregnancy Hypertens $7: 29-32,2017$

15. American College of Obstetricians and Gynecologists : Hypertension in pregnancy. Report of the American College of Obstetricians and Gynecologists' Task Force on Hypertension in pregnancy. Obstet Gynecol $122: 1122,2013$

16. Klein SJ, Brandtner AK, Lehner GF, Ulmer H, Bagshaw SM, Wiedermann CJ, Joannidis M : Biomarkers for prediction of renal replacement therapy in acute kidney injury : a systematic review and meta-analysis. Intensive Care Med 44(3) : 323-336, 2018

17. Yalman MV, Madendag Y, Sahin E, Madendag IC, Sahin ME, Acmaz G, Ozdemir F, Muhtaroglu S, Muderris II : Effect of preeclampsia and its severity on maternal serum NGAL and KIM-1 levels during pregnancy and the post-pregnancy period. Eur J Obstet Gynecol Reprod Biol $256: 246-251,2021$

18. Yolli H, Demir M, Yildizhan R : Neutrophil gelatinase associated lipocalin-2 (Ngal) levels in preeclampsia. Clinical and Experimental Obstetrics \& Gynecology 47(4) : 519-523, 2020

19. Karampas G, Eleftheriades M, Panoulis K : Maternal serum levels of neutrophil gelatinase-associated lipocalin
(NGAL), matrix metalloproteinase-9 (MMP-9) and their complex MMP-9/NGAL in pregnancies with preeclampsia and those with a small for gestational age neonate, a longitudinal study. Prenat Diagn 34(8) : 726-733, 2014

20. Kim S, Park J, Norwitz E, Jung H, Kim B, Park C, Jun $\mathrm{J}$ : Circulating levels of neutrophil gelatinase-associated lipocalin (NGAL) correlate with the presence and severity of preeclampsia. Reprod Sci 20 : 1083-1089, 2013

21. Ahmad S, Ghaznavi S, Rasheed N, Ikram M : Comparison of serum neutrophil gelatinase-associated lipocalin (NGAL) levels in pre-eclamptic and normotensive pregnant women. Rawal Medical Journal 45(1) : 154-157, 2020

22. Dhivya M, Mathew C, Jeyachandran G: Association of serum neutrophil gelatinase-associated lipocalin (NGAL) levels with preeclampsia. Int J Reprod Contracept Obstet Gynecol 8 (2) : 513-518, 2019

23. Gezer C, Ekin A, Ertas I, Ozeren M, Solmaz U, Mat E, Taner C : High first-trimester neutrophil-to-lymphocyte and platelet-to-lymphocyte ratios are indicators for early diagnosis of preeclampsia. Ginekologia Polska 87 : 431-435, 2016

24. Brinkmann V, Zychlinsky A : Neutrophil extracellular traps : is immunity the second function of chromatin? J Cell Biol 198: 773-783, 2012

25. Kang Q, Li W, Yu N, Fan L, Zhang Y, Sha M, Xiao J, Wu J, Kang Q, Chen S : Predictive role of neutrophil-to-lymphocyte ratio in preeclampsia : A meta-analysis including 3982 patients. Pregnancy Hypertens 20 : 111-118, 2020

26. Mannaerts D, Heyvaert S, De Cordt C, Macken C, Loos C, Jacquemyn Y : Are neutrophil/lymphocyte ratio (NLR), platelet/lymphocyte ratio (PLR), and/or mean platelet volume (MPV) clinically useful as predictive parameters for preeclampsia? J Matern Fetal Neonatal Med 32(9) : 14121419, 2019

27. Biyik I, Albayrak M, Keskin F : Platelet to Lymphocyte Ratio and Neutrophil to Lymphocyte Ratio in Missed Abortion. Revista Brasileira de Ginecologia e Obstetrícia 42(5) : 235-239, 2020

28. Song H, Kim H, Park K, Kim S, Oh S, Youn C : Neutrophil to lymphocyte ratio is associated with in-hospital mortality in older adults admitted to the emergency department. Am J Emerg Med 40 : 133-137, 2021

29. Argan O, Ural D, Kozdag G, Sahin T, Bozyel S, Aktas M, Karauzum Z, Yilmaz I, Dervis E, Agir A : Associations Between Neutrophil Gelatinase Associated Lipocalin, Neutrophil-to-Lymphocyte Ratio, Atrial Fibrillation and Renal Dysfunction in Chronic Heart Failure. Med Sci Monit 22 : 4765-4772, 2016 